\section{Nueva vacuna cuadrivalente contra el papilomavirus humano}

El papilomavirus humano (PVH) es la infección de transmisión sexual más común en los Estados Unidos de América, donde todos los años afecta a 6.200 .000 personas. Esta infección por lo general no produce síntomas clínicos y es autolimitada, pero la infección persistente con tipos oncógenos puede causar cáncer cervicouterino. Si bien esta enfermedad ha disminuido gracias al uso general de la prueba Papanicolaou (PAP) que detecta lesiones precancerosas del cuello uterino, se estima que en 2007 se diagnosticarán 11.000 casos nuevos y 3.700 mujeres perderán la vida como consecuencia de este cáncer. En países donde no se acostumbra el tamizaje regular por PAP, es una causa común de muerte en la mujer.

Se conocen alrededor de 100 tipos de PVH y más de 40 de ellos infectan la zona inguinal, por lo que se clasifican de acuerdo con su asociación epidemiológica con el cáncer cervicouterino. Las infecciones de bajo riesgo (p.ej., por los tipos 6 y 11) pueden causar cambios celulares inocuos o de escasa malignidad en el cuello uterino, verrugas genitales y otros cánceres de vulva, vagina, pene y ano, así como papilomatosis respiratoria recurrente. Los de alto riesgo (tipos 16, 18, 31, 33, 35, 39, 45, 51, 52, 56, $58,59,68,69,73$ y 82) funcionan como carcinógenos y se detectan en $99 \%$ de los cánceres de cuello uterino. En el ámbito mundial, cerca de $70 \%$ de estos cánceres son causados por los PVH tipos 16 y 18. Sin embargo, la mayoría de las mujeres con infecciones de alto riesgo no llegan a presentar cáncer. La mayor parte de esas infecciones son pasajeras y asintomáticas y no representan problemas clínicos. No se ha establecido con certeza ninguna relación entre los cánceres por PVH y otros no genitales, pero hay estudios que apuntan hacia una relación con cánceres de la zona malar y la faringe.

La infección genital por PVH se transmite principalmente por medio del coito y un número alto de parejas sexuales es un buen factor pronóstico de la infección. Otros factores de riesgo son tabaquismo, alta multiparidad, mayor edad, otras infecciones de transmisión sexual, uso prolongado de anticonceptivos, inmunodepresión y otros factores del huésped. El virus se transmite también, aunque con menos frecuencia, por medio de otros tipos de contacto sexual y de la madre al recién na- cido. Estas infecciones están protegidas de la respuesta inmunitaria del huésped porque radican en el epitelio, donde producen lesiones exofíticas. El virus se libera en las células deshojadas del epitelio y a veces se integra a los cromosomas del huésped, con poca producción de viriones. No todas las personas infectadas presentan anticuerpos; p.ej., $54 \%$ a $69 \%$ de las participantes en un estudio. El tiempo medio de seroconversión entre mujeres infectadas es de 8 meses. La infecciones de por sí no se tratan, pero sí las lesiones asociadas, lo cual no elimina la infección.

Dada la alta probabilidad de las adolescentes de adquirir la infección por PVH varios años después de iniciar la actividad sexual, en junio de 2006, el Comité Asesor sobre Prácticas de Inmunización (conocido en inglés por ACIP) autorizó el uso de una vacuna cuadrivalente para mujeres de 9 a 26 años de edad. Para llegar a esa decisión, un grupo de trabajo revisó minuciosamente datos publicados e inéditos sobre los resultados de ensayos clínicos de inocuidad, inmunogenicidad y eficacia, la historia natural del $\mathrm{PVH}$, aceptabilidad de la vacuna, comportamiento sexual de la población y análisis del costo. La disponibilidad de esta vacuna no eliminará la necesidad de tamizaje para el cáncer de cuello uterino, pero protege contra los tipos 6, 1116 y 18 precursores de varios cánceres y verrugas genitales. No protege contra infección persistente, lesiones precursoras de cáncer del cuello uterino, ni verrugas por otros tipos ya existentes al vacunar. Sin embargo, las mujeres ya infectadas por uno o más tipos de PVH antes de vacunarse están protegidas contra los efectos de los otros tipos incluidos en la vacuna.

La edad óptima para vacunación es a los 11 o 12 años, es decir antes de comenzar cualquier actividad sexual, pero puede administrarse a niñas de 9 y 10 años si es necesario y a mujeres de 13 a 26 que no se hayan vacunado antes. Se administra en tres dosis, con la segunda y tercera dos y seis meses después de la primera y puede administrarse a la misma vez que otras vacunas. La protección que confiere dura unos cinco años, pero se están llevando a cabo estudios de larga duración para corroborar ese aspecto.

Si bien el PVH es también común en los hombres, la vacuna cuadrivalente no ha sido aprobada para uso en ellos, pero se están llevando a cabo ensayos en ese sentido. Por ser una nueva vacuna, se 
continuarán realizando diversos estudios clínicos que aporten nuevos datos. También se considerará toda nueva información que se obtenga sobre la epidemiología del PVH y el ACIP modificará sus recomendaciones según sea apropiado. (Centers for Disease Control and Prevention. Quadrivalent Human Papillomavirus Vaccine. Recommendations of the Advisory Committee on Immunization Practices (ACIP). MMWR 2007;56(RR-2):1-19.)

\section{Cuatro colaboradoras en la metástasis del cáncer mamario}

El proceso metastásico involucra muchas funciones biológicas que colaboran para que las células cancerosas de un sitio primario se esparzan y lleguen a otros órganos distantes. A pesar de haberse avanzado en el diagnóstico y lucha contra el cáncer, hasta ahora se había descubierto muy poco acerca de las proteínas que facilitan su diseminación en el organismo.

Un grupo de investigadores internacionales se plantearon el problema de la metástasis de neoplasias de mama a los pulmones desde los puntos de vista genético y farmacológico. Trabajando con ratones, consiguieron mostrar que cuatro proteínas (la epirregulina, ligando receptor del factor de crecimiento epidérmico, la ciclooxigenasa Cox-2, y las metaloproteinasas matriciales 1 y 2 ), cuando se expresan en células cancerosas de las mamas, colaboran para facilitar la formación de nuevos vasos sanguíneos tumorales, la liberación de células tumorales en la circulación y la penetración de oncocélulas circulantes en las capilares de los pulmones para así sembrar la metástasis pulmonar. Estas proteínas se habían encontrado anteriormente en tumores metastásicos.

El estudio involucró la implantación de células metastásicas de cáncer de mama humano en tejidos saludables de mama de ratones. Algunas de las células así implantadas se habían producido por ingeniería genética de forma que los tumores no pudieran producir ninguna o algunas de las proteínas implicadas. Los tumores con el conjunto completo de proteínas crecieron rápidamente, mientras que el desarrollo fue lento en los que faltaban algunas de las proteínas. Los tumores que carecían de las cuatro dejaron de crecer. En otros experimentos, los tumores sin proteínas formaron vasos sanguíneos de poca extensión, con poca ramificación, mientras que los tumores productores de las proteínas echaron vasos muy ramificados y permeables de modo que podían dejar escapar oncocélulas en la sangre.

Puesto que la metástasis requiere no solo el desplazamiento de las células tumorales sino tam- bién que se arraiguen y crezcan en otro órgano, se hicieron aun otros ensayos para ver si se observaban efectos de la reducción de proteínas. La inyección intravenosa de células de cáncer de mama en los ratones mostró que la falta de las cuatro proteínas impedía que las células establecieran colonias en los pulmones.

También se llevó a cabo otra prueba en ratones que habían recibido oncocélulas dotadas de las cuatro proteínas, las cuales invadieron los pulmones. A algunos de esos animales se les administró una combinación de fármacos que suprimían las proteínas. En los que no recibieron estos supresores, en 24 días se comprobó crecimiento tumoral, mientras que en los ratones tratados se observaron solamente micrometástasis que permanecieron retenidas en las capilares de los pulmones sin mayor expansión. Fue evidente que las cuatro proteínas son mucho más eficaces cuando funcionan complementariamente.

Los resultados de este estudio revelan nuevos conocimientos sobre la metástasis: cómo las agresivas funciones oncógenas se pueden acoplar de forma mecanística con un mayor potencial pulmonar y cómo esas actividades biológicas pueden ser elegidas como objetivo específico de ciertas combinaciones farmacológicas. Sin embargo, algunos científicos han expresado dudas sobre la importancia de estos resultados diciendo que no es la primera vez que se haya curado el cáncer en ratones y que además los experimentos duraron muy poco —unas cuantas semanas- tiempo en el cual muchas personas también responden al tratamiento de las metástasis. También se ha criticado que la carga de cáncer impuesta a los ratones era menor de la que sostendría un ser humano con cáncer de mama.

Aun así, es de suma importancia que se haya podido identificar el grupo de proteínas que intervienen en la metástasis. Los fármacos que las suprimen incluyen dos medicamentos ya en el mercado: cetuximab, un agente antineoplásico, y celecoxib, un antiinflamatorio. El tercer fármaco es otro antiinflamatorio que inhibe las otras dos proteínas y que se ha probado en personas pero todavía no se ha lanzado al mercado. Los autores del estudio consideran que si se pueden inactivar las cuatro proteínas a la vez, se puede interferir la metástasis. Existen ya tratamientos para disminuir la posibilidad de la diseminación metastásica, de modo que podrían diseñarse ensayos para ver si la nueva combinación de fármacos representa alguna ventaja. También sería recomendable ampliar los estudios para determinar si las cuatro proteínas afectan la metástasis de cáncer de mama a otros órganos además de los pulmones. (Gupta GP, et al. Mediators of vascular remodeling co-opted for sequential steps in lung metastasis. Nature. 2007;446:765-770.) 